\title{
A Review of Hydrogen-Natural Gas Blend Fuels in Internal Combustion Engines
}

\author{
Antonio Mariani, Biagio Morrone and Andrea Unich \\ Dept. of Aerospace and Mechanical Engineering - Seconda Universitá degli Studi di Napoli \\ Italy
}

\section{Introduction}

In the last ten years, the number of natural gas (NG) vehicles worldwide has rapidly grown with the biggest contribution coming from the Asia-Pacific and Latin America regions (IANGV, 2011). As natural gas is the cleanest fossil fuel, the exhaust emissions from natural gas spark ignition vehicles are lower than those of gasoline-powered vehicles. Moreover, natural gas is less affected by price fluctuations and its reserves are more evenly widespread over the globe than oil. In order to increase the efficiency of natural gas engines and to stimulate hydrogen technology and market, hydrogen can be added to natural gas, obtaining Hydrogen - Natural Gas blends, usually named as HCNG.

This chapter gives an overview of the use of HCNG fuels in internal combustion engines. The chemical and physical properties of hydrogen and natural gas relevant for use in internal combustion engines are described. Then a survey on the impact of hydrogen on natural gas engine performance and emissions is presented with reference to research activities performed on this field.

\section{Data reduction}

In this section the main physical quantities used in this chapter are presented and discussed.

The stoichiometric air-fuel ratio on mass basis $\left(\mathrm{AFR}_{\text {stoich }}\right)$, defined in equation 1 , is the mass of air needed to fully oxidize $1 \mathrm{~kg}$ of fuel, while AFR is the ratio between air and fuel mass flow rates, equation 2. The ratio between the actual AFR and the $\mathrm{AFR}_{\text {stoich }}$, is the relative air-fuel ratio, equation 3 . If $\lambda>1$ the mixture is lean and the oxidation takes place with excess of air respect to the stoichiometric amount; for $\lambda$ values lower than 1 the mixture is rich, and the fuel oxidation is not complete. The ratio $1 / \lambda$ is defined as the equivalence ratio $\phi$, equation 4 .

$$
\begin{gathered}
A F R_{\text {stoich }}=\left(\frac{m_{a}}{m_{f}}\right)_{\text {stoich }} \\
A F R=\frac{m_{a}}{m_{f}} \\
\lambda=\frac{A F R}{A F R_{\text {stoich }}}
\end{gathered}
$$




$$
\phi=\frac{1}{\lambda}
$$

Equation 5 defines the indicated mean effective pressure (imep), an engine parameter which evaluates the work obtained by an engine cycle, $\oint p d V$, divided by the engine displacement. The Coefficient of Variation of imep, $\mathrm{COV}_{\text {imep }}$, is the ratio of the standard deviation of the indicated mean effective pressure and the average imep over a representative number of cycles, equation 6 .

$$
\begin{gathered}
\text { imep }=\frac{1}{V_{d}} \oint p d V \\
\text { COV } V_{\text {imep }}=\frac{\sigma_{\text {imep }}}{\text { imepavg }_{\text {avg }}}
\end{gathered}
$$

In case the effect of mechanical efficiency has to be taken into account, the brake mean effective pressure (bmep) is considered. In 4-stroke engines, the bmep is calculated from the torque measured at the engine shaft, according to equation 7 :

$$
\text { bmep }=\frac{T \cdot 4 \pi}{V_{d}}
$$

The stoichiometric reaction equation of a methane-hydrogen blend reads as:

$$
\left(\alpha \mathrm{CH}_{4}+\beta \mathrm{H}_{2}\right)+\left(2 \alpha+\frac{\beta}{2}\right)\left(\mathrm{O}_{2}+3.76 \mathrm{~N}_{2}\right) \rightarrow \alpha \mathrm{CO}_{2}+(2 \alpha+\beta) \mathrm{H}_{2} \mathrm{O}+\left(2 \alpha+\frac{\beta}{2}\right) 3.76 \mathrm{~N}_{2}
$$

where $\alpha+\beta=1$. The quantities $\alpha$ and $\beta$ represent the mole per each species in the blend, and it is immediate to observe that the reduction of the $\mathrm{C} / \mathrm{H}$ ratio, compared to pure methane, brings about a theoretical reduction of the $\mathrm{CO}_{2}$.

The burning velocity represents a main property for the combustion characteristics of the fuels and is defined as the velocity at which unburned gases move through the combustion wave in the direction normal to the wave surface (Glassman \& Yetter, 2008). The laminar burning velocities can be obtained using the following equation 9 (Mandilas et al., 2007) being $S_{S}$ the unstretched flame speed, $\rho_{b}$ and $\rho_{u}$ the burned and unburned gas densities. Equation 10 relates the unstretched flame speed, the stretched flame speed $S_{n}$, the stretch rate $\kappa$ and the Markstein length $\mathrm{L}_{b}$.

$$
\begin{gathered}
u_{l}=S_{s} \frac{\rho_{b}}{\rho_{u}} \\
S_{s}-S_{n}=\kappa L_{b}
\end{gathered}
$$

The stretch rate $\kappa$ is calculated from the position of the flame front, $R=R(t)$, with the following equation 11 (Chen, 2009):

$$
\kappa=\frac{1}{R} \frac{d R}{d t}
$$

The Markstein length characterizes the variation in the local flame speed due to the influence of external stretching and determines the flame instability with respect to preferential diffusion (Markstein, 1964). 


\section{Natural gas}

The main natural gas constituent is methane and the composition is strictly dependent on the origin gas field. Table 1 shows the composition of a natural gas sample obtained by the Italian distribution network, determined by means of gas chromatographic analysis.

Natural gas has been widely investigated as fuel for road vehicles because of its lower impact on the environment than gasoline and more widespread resources.

\begin{tabular}{|c|c|}
\hline Constituent & Composition [\% vol.] \\
\hline Methane & 88.98 \\
\hline Ethane & 6.85 \\
\hline Propane & 1.27 \\
\hline Butane & 0.24 \\
\hline Pentane & 0.04 \\
\hline Hexane & 0.003 \\
\hline Nitrogen & 0.96 \\
\hline Carbon dioxide & 1.61 \\
\hline
\end{tabular}

Table 1. Example of natural gas composition.

Ristovski et al. (2004) performed an experimental activity on a passenger car converted to operate either on gasoline or on compressed natural gas (CNG). Fuelling the engine by CNG, both regulated (CO, NOx and $\mathrm{HC}$ ) and unregulated emissions (PAHs and formaldehyde) were lower than gasoline.

Prati, Mariani, Torbati, Unich, Costagliola \& Morrone (2011) tested a bifuel passenger car fuelled alternatively by gasoline and natural gas on a chassis dynamometer over different driving cycles, in order to evaluate the effects of fuel properties on combustion, exhaust emissions and engine efficiency. The results showed that gasoline produced $\mathrm{CO}$ emissions higher than NG over the real world Artemis driving cycles, as a consequence of mixture enrichment during load transients. A detailed description of the driving cycles is reported in Barlow et al. (2009). Over the type approval New European Driving Cycle (NEDC), NG involved higher $\mathrm{HC}$ emissions compared to gasoline as a consequence of the higher light-off temperature for the catalytic oxidation of $\mathrm{CH}_{4}$, which is the major constituent of $\mathrm{HC}$ when the vehicle is fuelled by NG, while there were no differences over the Artemis driving cycles which were performed after a warming up conditioning of the vehicle. NOx emissions were higher for gasoline over all the test cycles. $\mathrm{CO}_{2}$ emissions for $\mathrm{CNG}$ showed a reduction between $21 \%$ and $29 \%$ over the tested driving cycles as a consequence of the reduced carbon content of the fuel and the lower fuel consumption on mass basis. A $5 \%$ fuel consumption reduction, expressed in $\mathrm{MJ} / \mathrm{km}$, is observed over the NEDC for the CNG respect to gasoline, while for the Artemis the reduction ranges between $10 \%$ and $22 \%$. The higher gasoline consumption is the consequence of the mixture enrichment during transients. Particulate emissions referred to gasoline were higher than NG ones over the NEDC and comparable over the Artemis. Particle number observed was also higher for gasoline, with the exception of the Artemis Motorway. 


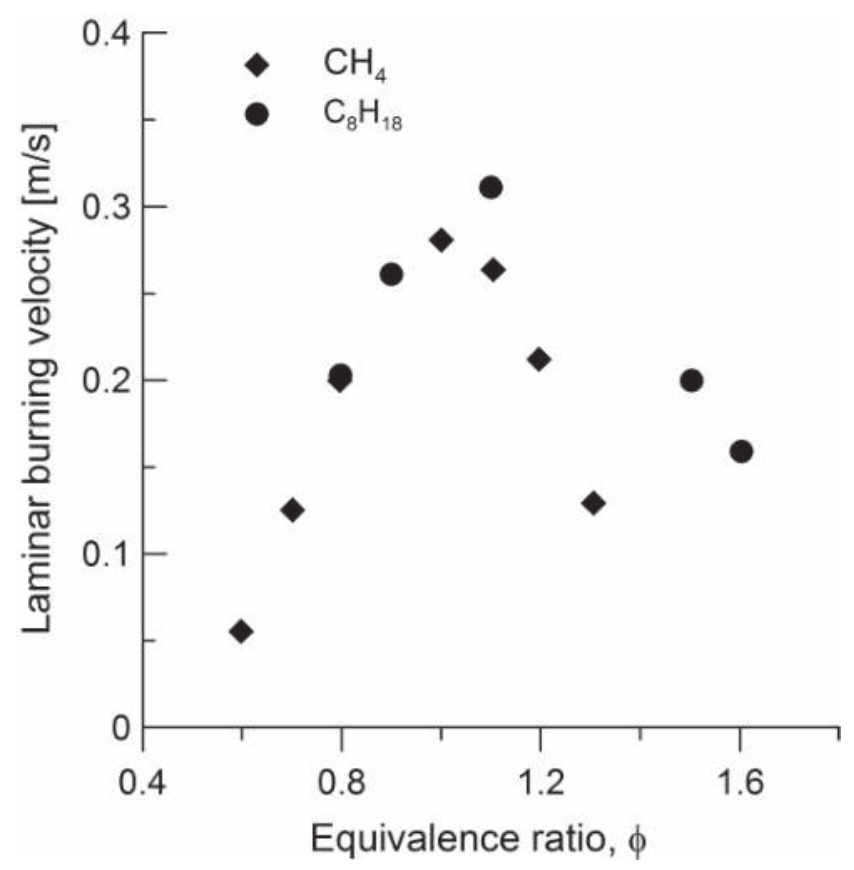

Fig. 1. Flame speeds of methane and iso-octane versus equivalence ratio $\phi$ (Mandilas et al., 2007).

One of the drawbacks of the NG fuel is the laminar burning velocity lower than gasoline, as shown in Figure 1 (Mandilas et al., 2007) requiring, as a consequence, a higher spark advance.

\section{Hydrogen production and storage}

\subsection{Hydrogen production}

The production of hydrogen is an important aspect since it is not present as a free chemical species in nature. Hydrogen can be produced in several ways, but reforming from fossil fuels or partial oxidation and electrolysis are the most employed from an industrial point of view.

The electrolysis consists in splitting the water molecule in hydrogen and oxygen as indicated in the next reaction equation:

$$
\mathrm{H}_{2} \mathrm{O}+\Delta h_{r} \rightarrow \mathrm{H}_{2}+\frac{1}{2} \mathrm{O}_{2}
$$

If the energy for water electrolysis is provided by renewable energy sources, hydrogen production is an environmental friendly process, without green-house gas emissions. Two main types of industrial electrolysis units are used today, which differ in the type of electrolyte adopted. The first type of electrolysers is characterised by an alkaline aqueous solution of $25-35 \%$ in weight of potassium hydroxide $(\mathrm{KOH})$ to maximise the ionic conductivity, in which the hydroxide ions $\left(\mathrm{OH}^{-}\right)$are the charge carriers (Ulleberg, 2003). In the second type 
of electrolysers the electrolyte is an ion conducting membrane that allows $\mathrm{H}^{+}$ions to be transported from the anode to the cathode side to recombine forming hydrogen. They are known as Proton Exchange Membrane (PEM) electrolysers (Barbir, 2005). However, water electrolysis powered by renewable energy sources is not competitive considering the current energy costs but it may become more economical in the future (Bartels et al., 2010).

The nowadays most economical sources of hydrogen are coal and natural gas, with significant experience in the operation of these types of plants, which will continue to be built and operated. The fuel reforming is a process in which hydrocarbon fuels, such as natural gas, are converted into a hydrogen-rich reformate gas. A reformer accomplishes the task by thermo-chemically processing hydrocarbon feedstock in high temperature reactors with steam and/or oxygen. Effective reformers should efficiently produce pure hydrogen with low pollutants emission. The methane steam reforming global reaction is reported as an example in the following reaction 13.

$$
\mathrm{CH}_{4}+\mathrm{H}_{2} \mathrm{O} \rightarrow \mathrm{CO}+3 \mathrm{H}_{2}+\Delta h_{r}
$$

The reformate gas is composed of $40 \%-70 \%$ hydrogen by volume and carbon monoxide, carbon dioxide, water, nitrogen and traces of other compounds. The water-gas shift conversion removes $\mathrm{CO}$ and increases hydrogen content. Shift step takes place at high temperatures of about $350-480^{\circ} \mathrm{C}$, followed by a low-temperature shift $\left(180-250^{\circ} \mathrm{C}\right)$.

\subsection{Hydrogen storage}

Hydrogen has been recognized as an ideal energy carrier but it has not yet been widely employed in the transportation sector. The lack of an efficient storage prevents its application, in particular as fuel for transportation. Because of the low density of hydrogen at ambient conditions, it is a challenge to store enough energy on-board to allow for an acceptable vehicle range. The density can be increased by pressurizing or liquefying hydrogen. High-pressure gaseous hydrogen, up to 700 bars, is considered a potential safety hazard due to problems of material resistance. For vehicle application, cylinders are made of composite fibre due to weight considerations. Indeed, tanks add a relevant weight to the vehicle, much greater than the stored fuel, which is the $3 \%$ of the total weight (cylinder plus fuel) for a 700 bars approved system (Sørensen, 2005).

Liquid hydrogen storage requires refrigeration to a temperature of about $20 \mathrm{~K}$, and the liquefaction process requires at least $15.1 \mathrm{MJ} / \mathrm{kg}$. The on-board storage pressures for the liquid hydrogen are only slightly above the atmospheric, with typical values around 6 bars. The vessel for storing liquid hydrogen consists of several metal layers separated by highly insulating materials. The main drawback is the hydrogen boil-off from the storage caused by the need to control tank pressures by venting valves. Boil-off usually starts after a dormancy period and then proceeds at a level of 3\% - 5\% per day (Sørensen, 2005).

As an alternative, even more challenging options have been proposed and investigated. Most attention is paid to storage in solid materials and especially metal hydrides. Here, hydrogen gas is fed to a tank containing a metal powder and is absorbed as hydrogen atoms in the metals crystal lattice to form a metal hydride. In metal hydrides, hydrogen can be stored with energy densities up tp $15000 \mathrm{MJ} / \mathrm{m}^{3}$, higher than that of liquid hydrogen, which is 8700 
$\mathrm{MJ} / \mathrm{m}^{3}$ (Sørensen, 2005). The main disadvantage, however, is the weight of the storage alloys. Furthermore refuelling times are affected by absorption rates.

Other storage options are under investigation but still at prototypal stage (Bakker, 2010).

\section{HCNG blends}

Table 2 compares the main physical properties for pure fuels, methane and hydrogen. In the same table, LHV represents the Lower Heating Value of the fuel, AFR is the air-to-fuel ratio and $\mathrm{LHV}_{\text {stoich, mix }}\left[\mathrm{MJ} / \mathrm{Nm}^{3}\right]$ is the volumetric lower heating value for a stoichiometric air-fuel mixture.

\begin{tabular}{|l|c|c|}
\hline & $\mathbf{C H}_{\mathbf{4}}$ & $\mathbf{H}_{\mathbf{2}}$ \\
\hline Adiabatic flame temperature of stoichiometric mixtures [K] $]$ & 2210 & 2400 \\
\hline Flammability limits in air at $25^{\circ} \mathrm{C}$ and 1 bar $[\%$ vol.] & $5.0-15$ & $4.0-75$ \\
\hline Minimum ignition energy in air at $\phi=1$ and 1 bar $[\mathrm{mJ}]$ & 0.47 & 0.02 \\
\hline $\mathrm{LHV}[\mathrm{MJ} / \mathrm{kg}]$ & 50.0 & 120.3 \\
\hline $\mathrm{LHV}_{\text {vol }}\left[\mathrm{MJ} / \mathrm{Nm}^{3}\right]$ & 35.3 & 10.6 \\
\hline $\mathrm{AFR}_{\text {stoich }}$ & 17.2 & 34.3 \\
\hline $\mathrm{LHV}_{\text {stoich, } \text { mix }}\left[\mathrm{MJ} / \mathrm{Nm}^{3}\right]$ & 3.351 & 3.143 \\
\hline
\end{tabular}

Table 2. $\mathrm{CH}_{4}$ and $\mathrm{H}_{2}$ properties (Glassman \& Yetter, 2008).

Table 3 shows the main fuel characteristics of natural gas and hydrogen-natural gas blends with 10\% (HCNG10), 20\% (HCNG20) and 30\% (HCNG30) of hydrogen in volume. The volumetric hydrogen content is calculated according to equation 14.

$$
H_{2}[\% \text { oll. }]=\frac{V_{H_{2}}}{V_{N G}+V_{H_{2}}}
$$

The volumetric Lower Heating Value is the fuel energy per unit volume, so it is a measure of the energy that can be stored in the fuel tank. It is 7\% lower than NG for HCNG10, 14\% for HCNG20 and $21 \%$ for HCNG30. LHV stoich, mix, which is proportional to the engine power output, is negligibly affected by hydrogen addition.

\begin{tabular}{|l|c|c|c|c|}
\hline & Natural Gas & HCNG10 & HCNG20 & HCNG30 \\
\hline $\mathrm{H}_{2}[\%$ vol.] & - & 10 & 20 & 30 \\
\hline $\mathrm{H}_{2}[\%$ energy] & - & 3.2 & 7.0 & 14.4 \\
\hline $\mathrm{LHV}[\mathrm{MJ} / \mathrm{kg}]$ & 45.3 & 46.2 & 46.7 & 48.5 \\
\hline $\mathrm{LHV}_{\text {vol }}\left[\mathrm{MJ} / \mathrm{Nm}^{3}\right]$ & 36.9 & 34.3 & 31.7 & 29.2 \\
\hline $\mathrm{AFR}_{\text {stoich }}$ & 15.6 & 15.8 & 16.1 & 16.4 \\
\hline $\mathrm{LHV}_{\text {stoich, mix }}\left[\mathrm{MJ} / \mathrm{Nm}^{3}\right]$ & 3.375 & 3.367 & 3.358 & 3.349 \\
\hline
\end{tabular}

Table 3. NG and HCNG fuel properties. 


\subsection{Combustion characteristics}

Since hydrogen laminar combustion speed is about eight times greater than methane, it provides a reduction of combustion duration when mixed with natural gas in small concentrations. Many studies have been carried out to measure the flame speed of hydrogen-methane air mixtures at different hydrogen concentrations and equivalence ratios. Ilbas et al. (2006) performed the measurements at ambient temperatures with hydrogen-methane blends up to $100 \%$ hydrogen.

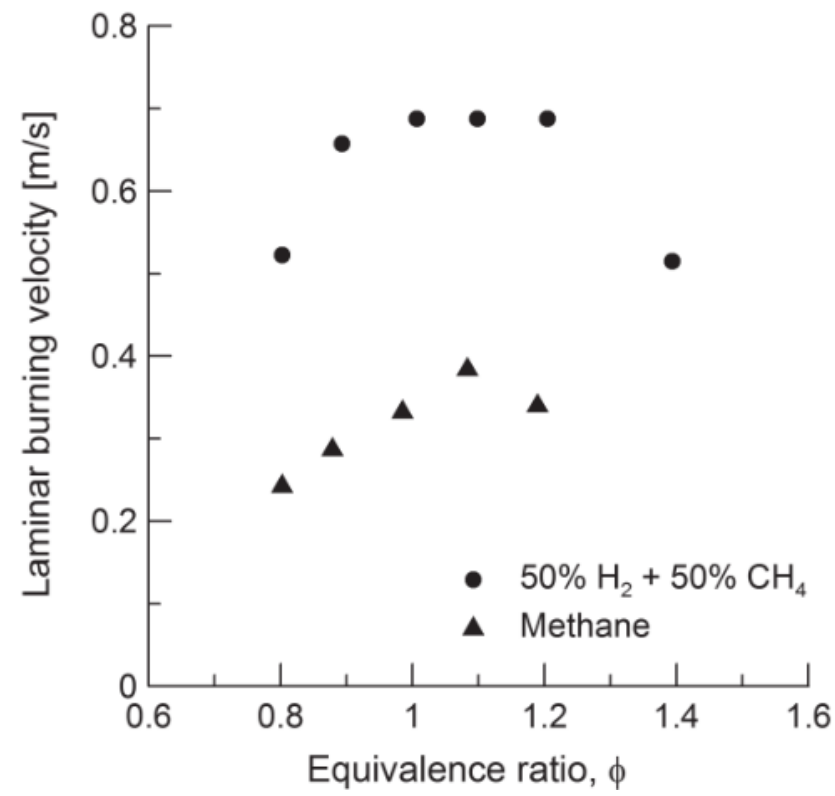

Fig. 2. Flame speed of different fuels versus equivalence ratio $\phi$ (Ilbas et al., 2006).

Figure 2 shows the flame speed for methane and a 50\% hydrogen-methane blend plotted versus the equivalence ratio. The maximum flame speed for the blend is $0.69 \mathrm{~m} / \mathrm{s}$ while the maximum for methane is $0.39 \mathrm{~m} / \mathrm{s}$ for an equivalence ratio $\phi=1.1$. The flammable regions were also widened as the hydrogen content increased in the mixtures.

Figure 3, where the flame speed is plotted versus hydrogen content, shows the non-linear dependence of this property on hydrogen percentage.

Mandilas et al. (2007) performed experiments in a spherical stainless steel vessel at initial temperatures up to $600 \mathrm{~K}$ and initial pressures up to $1.5 \mathrm{MPa}$ to study the effects of hydrogen addition on laminar and turbulent premixed methane-air flames. The burning velocity, $\mathrm{u}_{l}$, was found using equation 9. Methane can be ignited for $0.6 \leq \phi \leq 1.3$, with the peak burning velocity occurring at $\phi=1.0$. The addition of $\mathrm{H}_{2}$ extends the ignition limits to the range $0.5 \leq \phi \leq 1.4$ and increases the values of $\mathrm{u}_{l}$ at lean equivalence ratios, while $\mathrm{u}_{l}$ does not increase for rich equivalence ratios. The authors also compared the turbulent velocity $\mathrm{u}_{t r}$ for methane and a blend with 30\% of hydrogen. As in the laminar case, the addition of hydrogen 


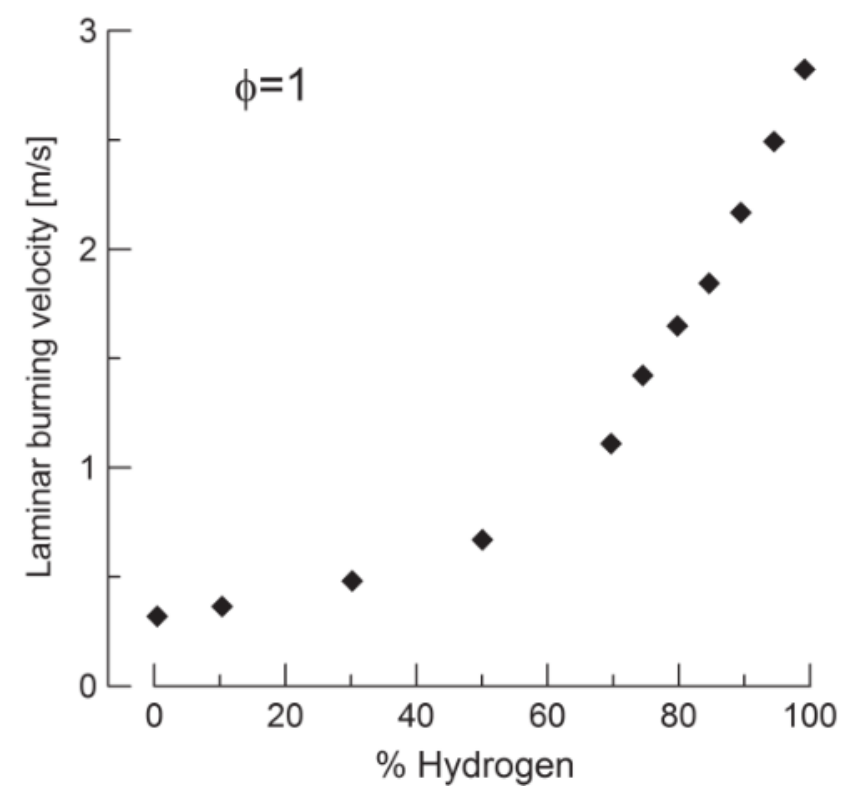

Fig. 3. Flame speeds versus hydrogen content in methane-hydrogen blends at $\phi=1$ (Ilbas et al., 2006).

extends the ignition limits and higher $\mathrm{u}_{t r}$ values, in particular at lean air-fuel mixtures, are attained compared to methane.

A comparison of results obtained by several authors for the unstretched laminar burning velocity versus the equivalence ratio, for HCNG20, is shown in Figure 4 (Miao et al., 2009). It is observed in any case that the maximum flame speed is attained at $\phi \cong 1.1$ with values around $0.5 \mathrm{~m} / \mathrm{s}$.

\subsection{The impact of HCNG blends on engine efficiency and exhaust emissions}

The reduction of combustion duration promoted by hydrogen addition results in increased engine efficiency respect to natural gas and enhances combustion stability, reducing cycle-by-cycle variation. Nagalingam et al. (1983) proved that the high burning rate of HCNG blends requires an ignition timing lower than natural gas to obtain the Maximum Brake Torque (MBT).

The MBT spark advance versus the hydrogen content, shown in Figure 5 (Karim et al., 1996), is noticeably affected by hydrogen addition, in particular for very lean air-fuel mixtures. The plot shows that for blends containing significant amount of hydrogen, small adjustments to the ignition timing are needed when the equivalence ratio is changed.

The engine efficiency can be increased fuelling the engine by HCNG blends. Sierens \& Rosseel (2000) developed a fuel system which supplies hydrogen-natural gas mixtures in variable proportion to the engine. For low brake mean effective pressures high efficiency can be achieved by increasing the hydrogen content reducing throttling losses. The authors 


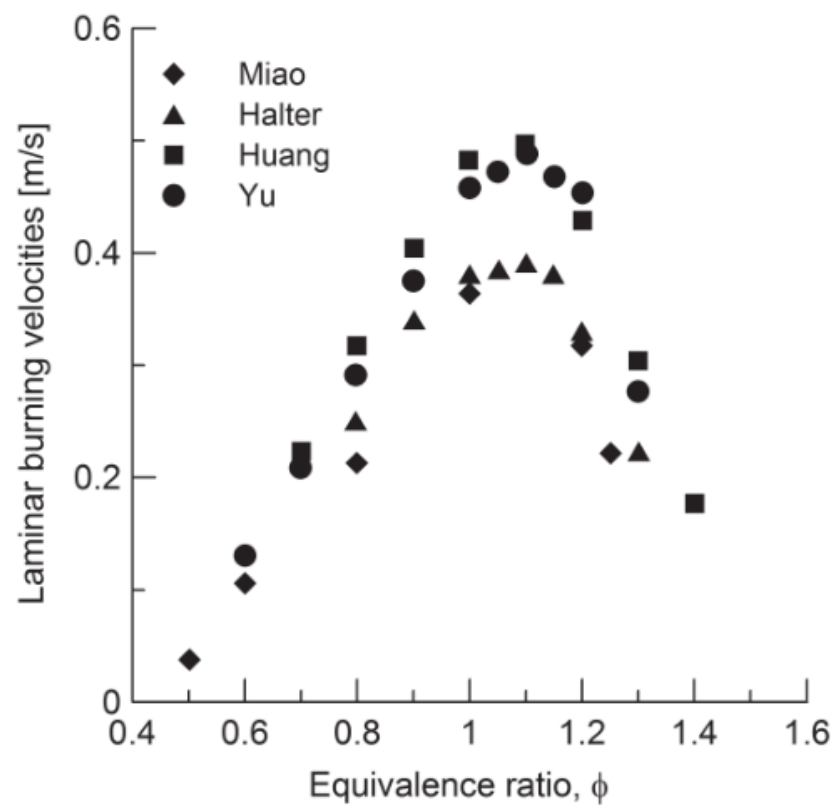

Fig. 4. Unstretched laminar burning velocity $u_{l}$ versus the equivalence ratio $\phi$ for HCNG20 (Miao et al., 2009).

found that $10 \%$ hydrogen increases engine efficiency moderatly whereas $20 \%$ hydrogen gives negligible extra benefit, as shown in Figure 6.

Recently, Ma et al. (2010) investigated the effect of high hydrogen volumetric content, up to $55 \%$, on the performance of a turbocharged lean burn natural gas engine. The authors found that the addition of hydrogen significantly extends the lean limit, decreases burn duration and yields higher thermal efficiency. The plot of the engine efficiency versus $\lambda$, Figure 7 , shows a negative trend in engine efficiency for natural gas for $\lambda$ values greater than 1.3, while the blend with the higher hydrogen content shows positive trend up to $\lambda=1.6$.

The increased hydrogen/carbon ratio and engine efficiency bring a reduction of $\mathrm{CO}_{2}$ emissions. By the way, as a consequence of a faster combustion, higher temperature are attained in the combustion chamber, increasing NOx emissions in HCNG fuelled engines compared to natural gas, for a given equivalence ratio $\phi$. NOx can be kept down and engine efficiency further improved if the engine is run with lean mixtures or adopting EGR at stoichiometric air-fuel ratio.

Sierens \& Rosseel (2000) found the maximum NOx emissions at a relative air-fuel ratio $\lambda=1.1$. For higher $\lambda$ values, the reduction in heat of combustion available for the charge mixture reduces the temperature and NOx as a consequence, as shown in Figure 8. However, such conditions cause an increase in THC emissions, as shown in Figure 9.

Hoekstra et al. (1995) obtained very low NOx emissions operating with HCNG blends close the lean limit, significantly extended compared with natural gas. Besides, the excellent anti 


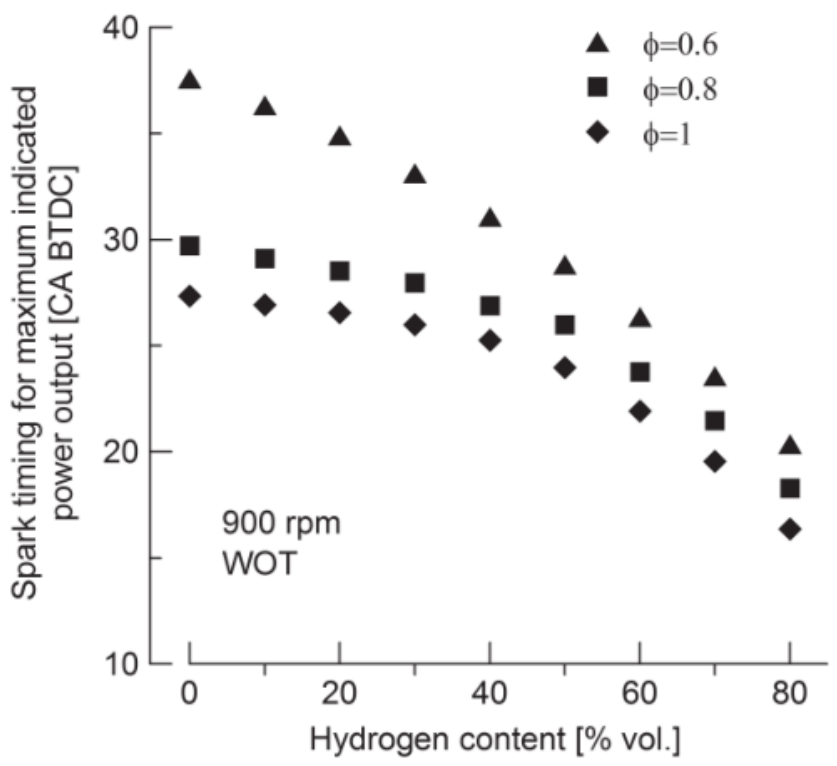

Fig. 5. Spark timing for maximum indicated power output versus hydrogen content (Karim et al., 1996).

knock qualities of natural gas are not undermined by the presence of relatively small amounts of hydrogen in the blend (Karim et al., 1996).

The effect of hydrogen on the lean limit, here defined as the $\lambda$ value at which the $\mathrm{COV}_{\text {imep }}$ attains 10\%, is shown in Figure 10 (Ma et al., 2010), with values of 1.2 for NG, 2.1 for HCNG30 and 2.5 for HCNG55.

The impact of hydrogen addition to natural gas on cycle-by-cycle variations have been investigated in many scientific activities and the results showed that the coefficient of variation in maximum pressure and in indicated mean effective pressure are reduced with increasing hydrogen content, both with lean air-to-fuel ratio as well described by Ma et al. (2008) in Figure 11 and Wang et al. (2008) and with large exhaust gas recirculation ratio values, Figure 12 (Huang et al., 2009).

Numerical simulations have also been used to predict performance and emissions of internal combustion engines fuelled by HCNG blends.

Figure 13 shows the predicted fuel consumption in terms of energy per kilometer $[\mathrm{MJ} / \mathrm{km}]$ over the NEDC versus the hydrogen content (Mariani et al., 2011). Stoichiometric air-to-fuel ratio was considered for each fuel in order to assure an efficient exhaust after-treatment adopting a three-way catalyst. Exhaust gas recirculation was investigated (instead of ultra lean mixture) with the aim at improving engine efficiency and reducing NOx emissions respect to undiluted charge. In fact, HCNG blends combustion properties are particularly suitable for EGR, assuring a stable combustion even if the charge is diluted (Hu et al., 2009). 


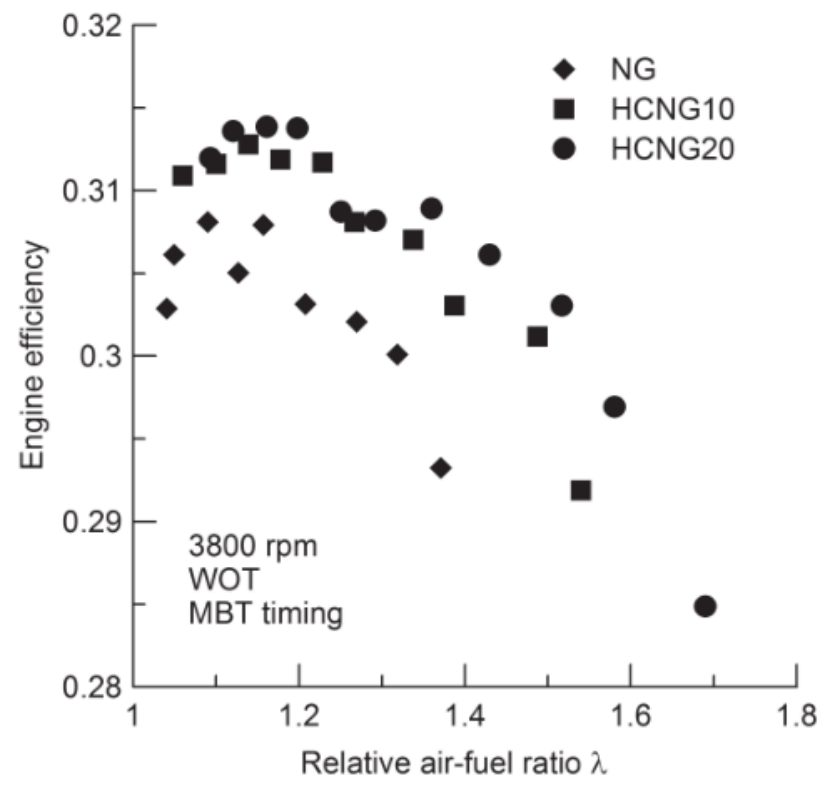

Fig. 6. Engine efficiency versus relative air-fuel ratio $\lambda$ for different fuels (Sierens \& Rosseel, 2000).

MBT ignition timing has been adopted for all fuels and operating conditions investigated. Fuel consumption is reduced as the hydrogen content increases due to the positive effect on average engine efficiency over the driving cycle, with values $2.5 \%, 4.7 \%$ and $5.7 \%$ lower than NG for HCNG10, 20 and 30 respectively. Fuel consumption is further reduced adopting 10\% EGR for HCNG blends, with values 5.4\%, 6.6\% and 7.7\% lower than NG for HCNG10, 20 and 30 respectively. NOx emissions, expressed in $\mathrm{g} / \mathrm{km}$ over the driving cycles, are reported in Figure 14. Adding hydrogen higher in-cylinder temperatures are attained as a consequence of a faster combustion, resulting in increased NOx emissions with values $3.6 \%, 10.7 \%$ and $19.7 \%$ higher than NG for HCNG10, HCNG20 and HCNG30 respectively. The use of EGR results in lower NOx emissions with respect to the case without EGR, with values about $85 \%$ lower than CNG for each HCNG fuel.

\section{Real-life cases of HCNG use}

HCNG blends can be distributed by the present natural gas refuelling stations, providing them with a mixing equipment in order to obtain blends with the selected hydrogen content. The system must operate to assure a high accuracy of hydrogen percentage because the fuel composition influences engine performances hence requiring customized engine calibration. In particular, the increased combustion velocity requires a reduction of the ignition advance as the hydrogen concentration increases to obtain the maximum engine torque. Furthermore, the fuel supply system should be calibrated to compensate the variation of fuel properties caused by hydrogen addition. In fact, present natural gas vehicles requires stoichiometric air-fuel ratio to obtain a high conversion efficiency of $\mathrm{HC}, \mathrm{CO}$ and $\mathrm{NOx}$ emissions in the three-way 


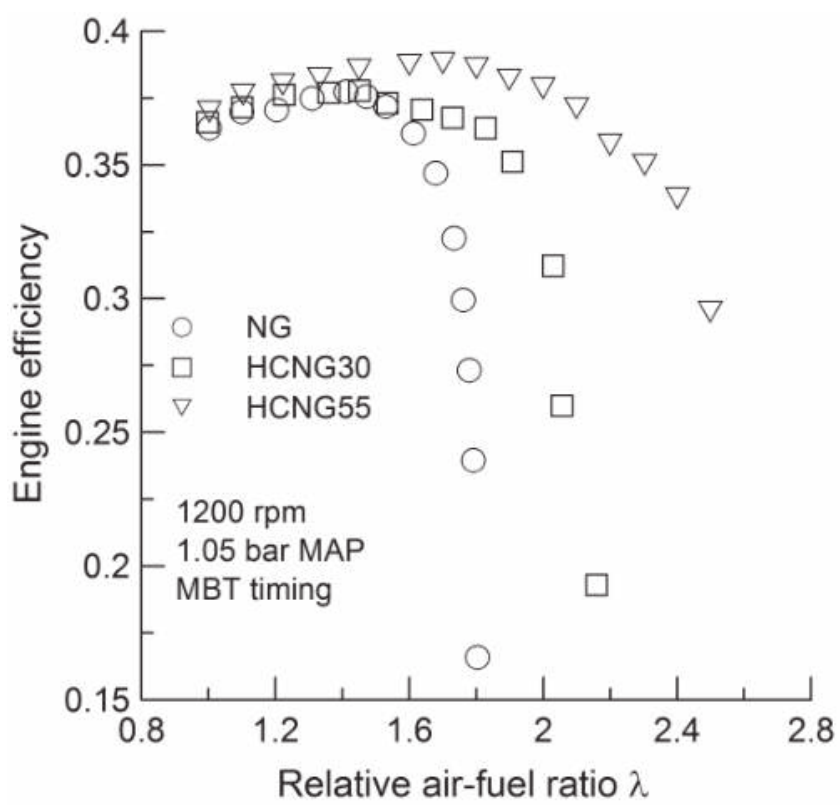

Fig. 7. Engine efficiency versus relative air-fuel ratio $\lambda$ for different fuels (Ma et al., 2010).

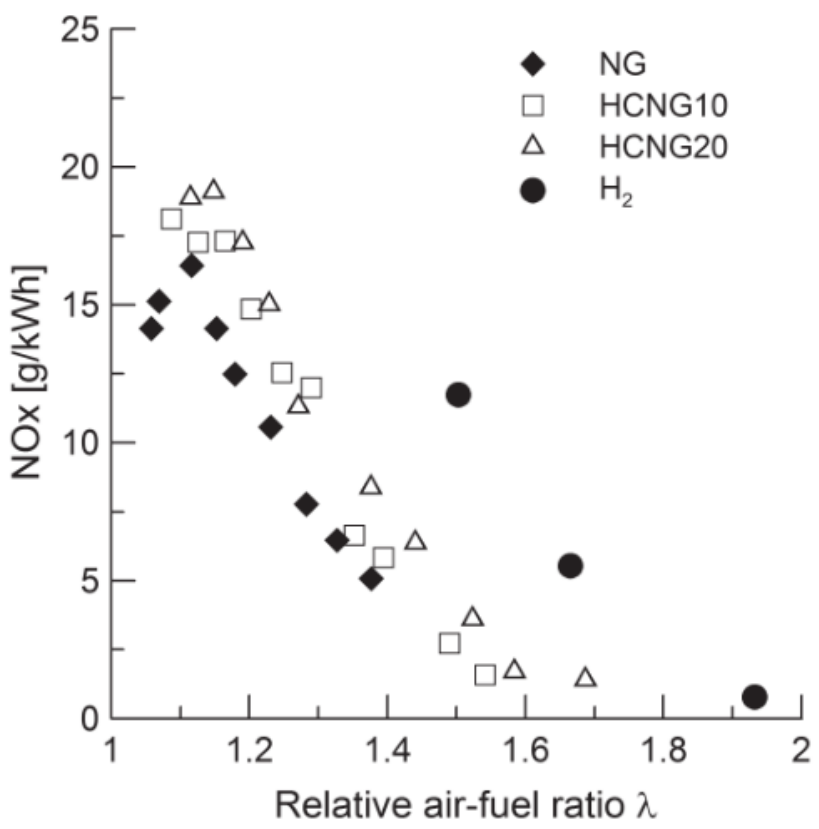

Fig. 8. NOx emissions versus relative air-fuel ratio $\lambda$ (Sierens \& Rosseel, 2000). 


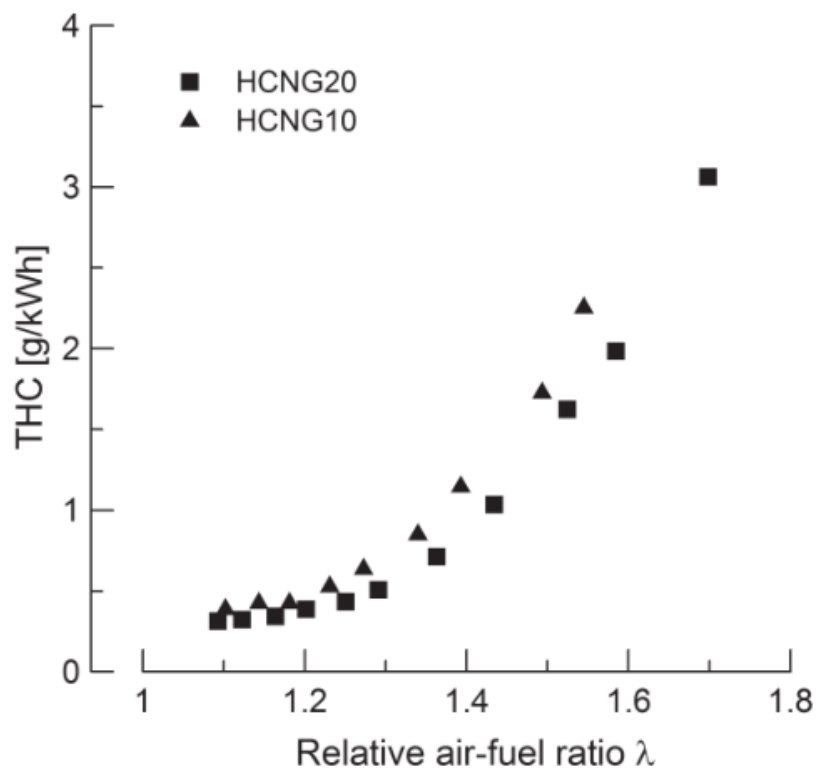

Fig. 9. Hydrocarbon emission versus relative air-fuel ratio $\lambda$ (Sierens \& Rosseel, 2000).

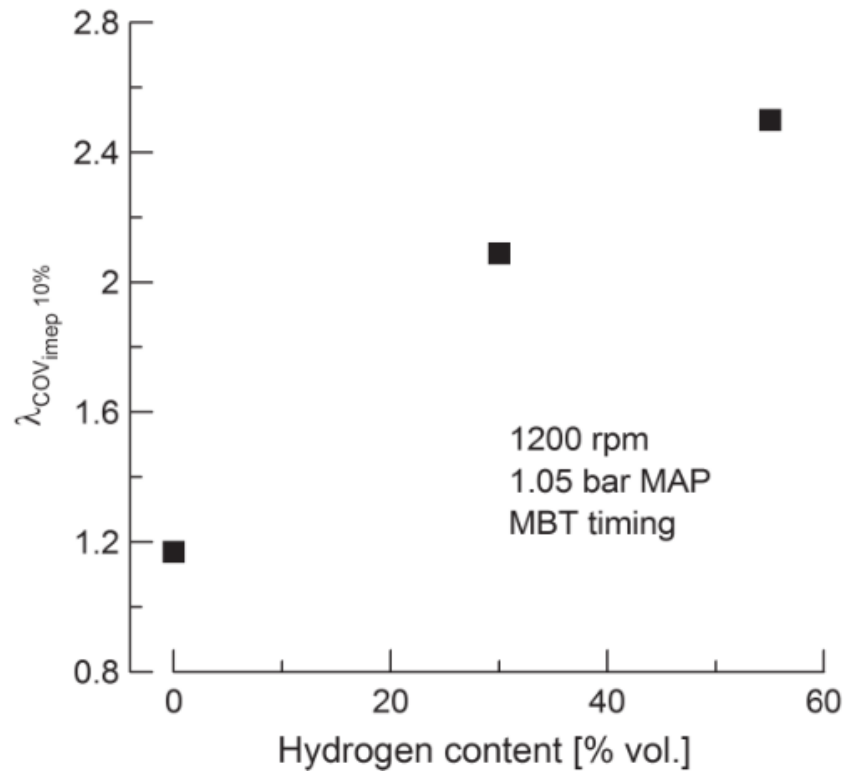

Fig. 10. Lean limit versus hydrogen content in the blend (Ma et al., 2010). 


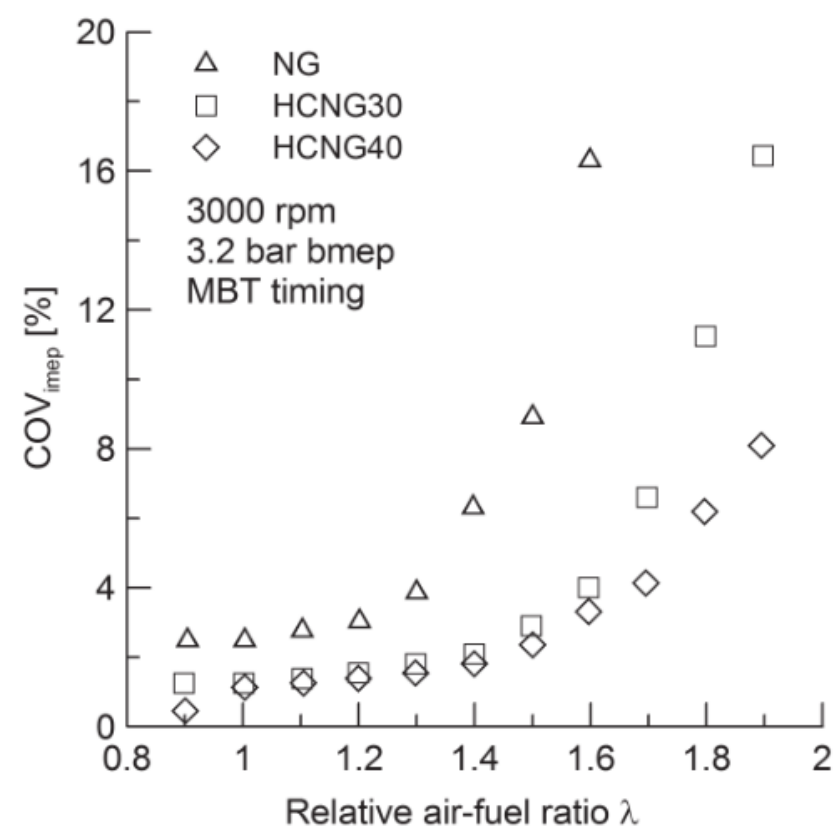

Fig. 11. COV $V_{\text {imep }}$ versus relative air-fuel ratio $\lambda$ for NG and HCNG blends (Wang et al., 2008).

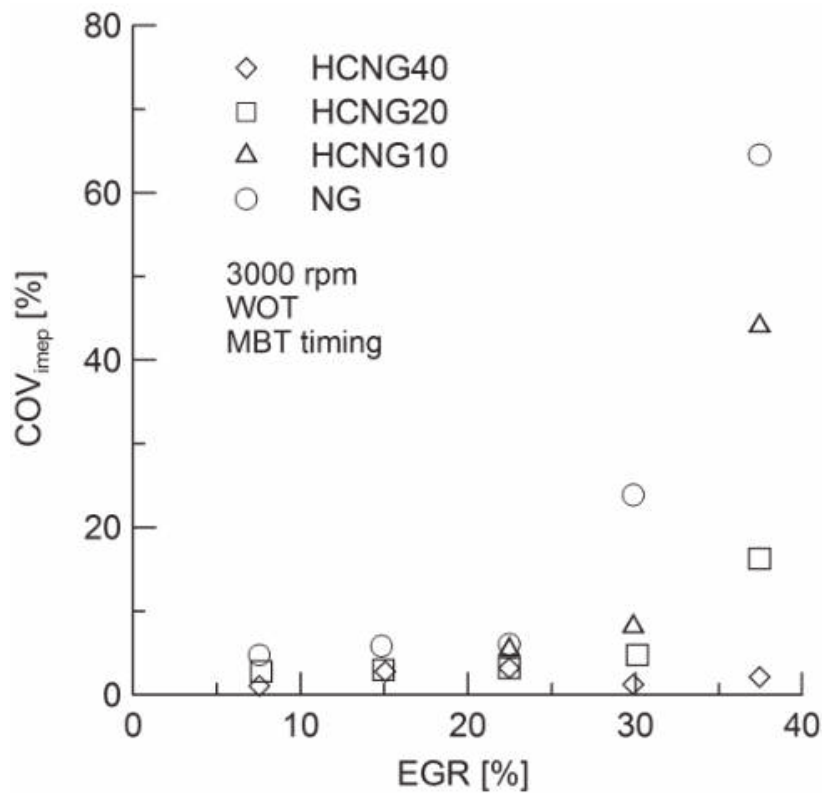

Fig. 12. COV $V_{\text {imep }}$ versus EGR for NG and HCNG blends (Huang et al., 2009). 


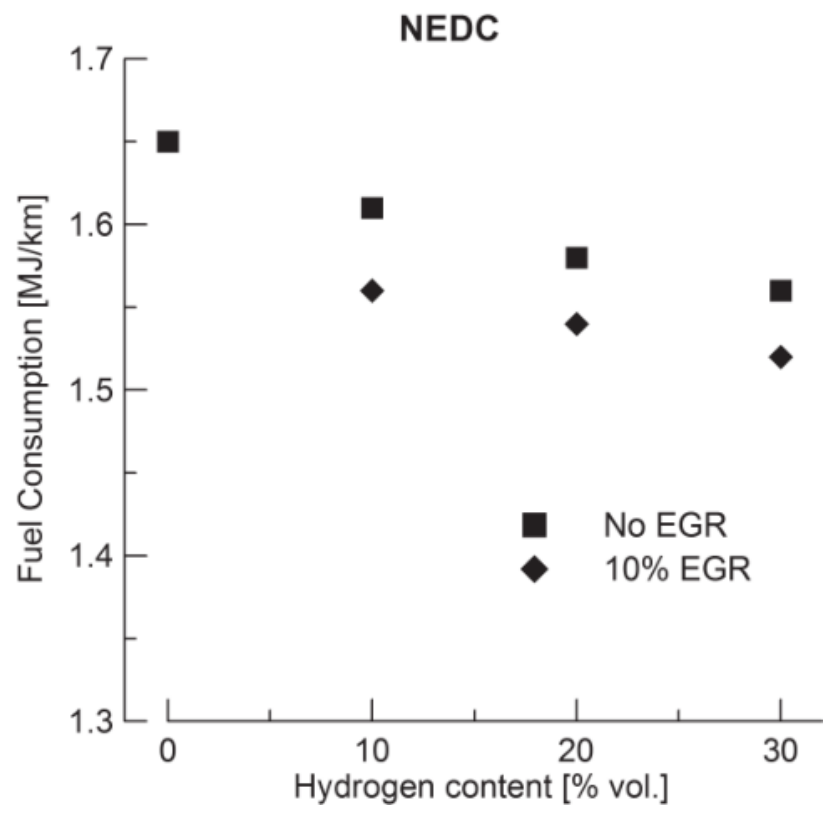

Fig. 13. Predicted fuel consumption versus hydrogen content over the NEDC (Mariani et al., 2011).

catalytic converter. HCNG fuels can be used in lean burn engines or with high EGR rates at stoichiometric conditions, exploiting their excellent combustion properties, with positive impact on engine efficiency and low exhaust emissions.

Finally, the use of HCNG fuel can stimulate the development of the hydrogen technologies and market which are, nowadays, the main practical problems preventing it to be implemented.

Many research projects have been performed in the past and others are still going on to assess the potential benefits coming by using HCNG fuels in real-life applications. The U.S. Department of Energy Advanced Vehicle Testing Activity (AVTA) teamed with Electric Transportation Applications (ETA) and Arizona Public Service (APS) to develop a hydrogen pilot plant, where hydrogen is produced by means of PEM electrolyzer and is dispensed to vehicles that operate with different HCNG blends with hydrogen ranging from $0 \%$ to $100 \%$. The project demonstrated the safety of operating vehicles on hydrogen and the reduction of exhaust emissions attainable with hydrogen and HCNG fuelled vehicles compared to gasoline (Francfort \& Karner, 2006).

A hydrogen production plant with HCNG dispenser have been built in Malmö, Sweden, for project to improve engine efficiency and reduce emissions of a bus fleet (Ridell, 2006).

In Italy, public transportation companies of Regione Emilia Romagna and the ENEA research center are involved in experimental tests to evaluate fuel consumption and exhaust emissions of buses for urban transport service, Figure 15 (Genovese et al., 2011). 


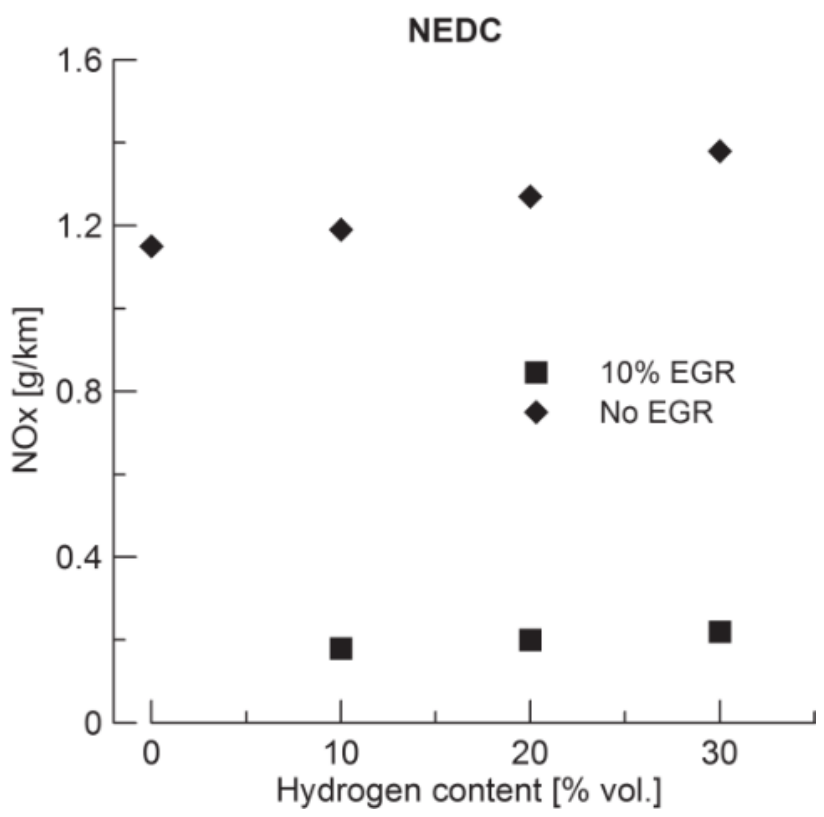

Fig. 14. Predicted NOx emissions versus hydrogen content over the NEDC (Mariani et al., 2011).

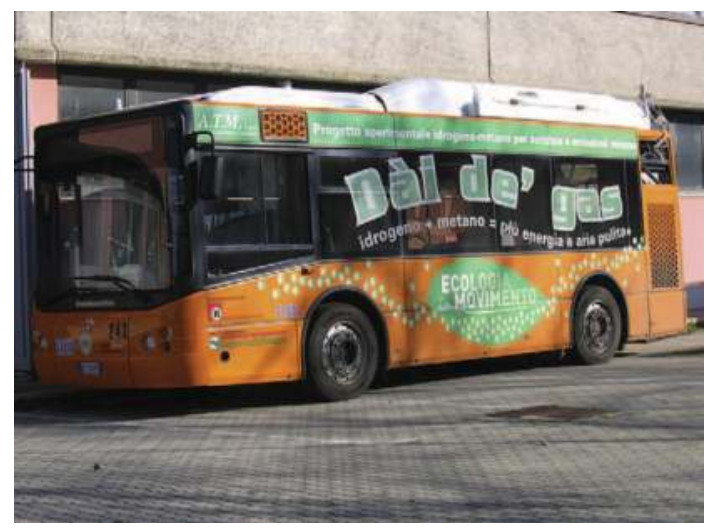

Fig. 15. Urban bus tested with HCNG blends (Genovese et al., 2011).

Regione Lombardia, Fiat Research Center, Sapio, CNR-Istituto Motori and Seconda Universitá degli studi di Napoli are involved in a project to test a passenger car fuelled by HCNG blends, varying the hydrogen content, in order to assess the impact of hydrogen addition to natural gas on combustion, exhaust emissions and fuel consumption, over different driving cycles, Figure 16 (Prati, Costagliola, Torbati, Unich, Mariani, Morrone \& Gerini, 2011). 
The authors of this review have designed and built an high accuracy mixing equipment to produce HCNG blends with imposed hydrogen content. The device is developed on the occasion of a project which involves the research group of the Seconda Universitá degli Studi di Napoli, the Neapolitan Transportation Company (CTP), NA-MET, the company managing the NG bus fleet and ECOS srl, an enterprise which develops CNG fuelling stations.

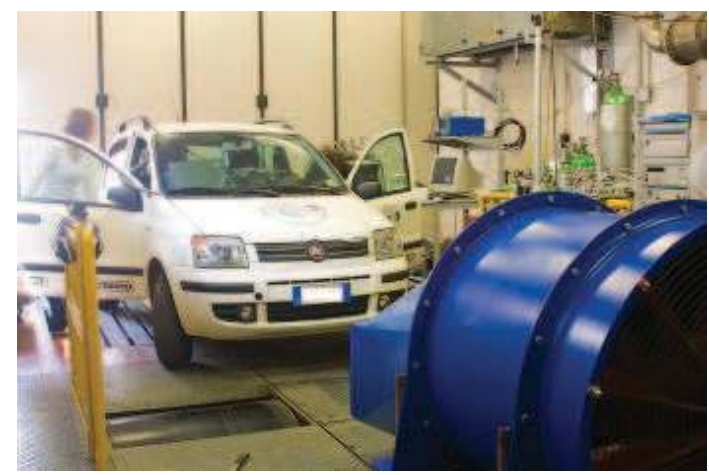

Fig. 16. Fiat Panda HCNG tested in the laboratory of Istituto Motori-CNR (Prati, Costagliola, Torbati, Unich, Mariani, Morrone \& Gerini, 2011).

\section{Conclusion}

Natural gas is employed as fuel since it is the cleanest fossil fuel with exhaust emissions from natural gas vehicles lower than those of gasoline-powered vehicles. Some of its drawbacks can be mitigated by enriching it with hydrogen to produce the so called hydrogen-natural gas blends.

The laminar flame speed of methane is lower than the gasoline one and the addition of hydrogen, which presents a laminar flame speed about eight times that of methane, significantly improves this main combustion property.

In the past years, many authors have proved both experimentally and numerically that the $\mathrm{HCNG}$ blends improve engine efficiency and reduce $\mathrm{CO}_{2}$ emissions because of the reduced $\mathrm{C} / \mathrm{H}$ ratio and fuel consumption. NOx emissions are, instead, larger than NG because of the higher in-cylinder temperature attained, for a given equivalence ratio. Anyway, the use of lean AFR or the EGR definitely reduces NOx emissions and bring about an extra increase in engine efficiency. The good combustion patterns of HCNG blends help to keep low HC emissions.

\section{Acknowledgements}

This work has been supported by a PRIST 2008 grant by the Seconda Universitá degli studi di Napoli, together with a 2011 research grant funded by the Seconda Universitá degli studi di Napoli. 


\section{Nomenclature}

\begin{tabular}{|c|c|}
\hline AFR & Air-fuel ratio $\left[\mathrm{kg}_{\text {air }} / \mathrm{kg}_{\text {fuel }}\right]$ \\
\hline avg & Average \\
\hline CA & Crank angle $\left[{ }^{\circ}\right]$ \\
\hline $\mathrm{COV}$ & Coefficient of variation \\
\hline BTDC & Before top dead center \\
\hline EGR & Exhaust gas recirculation \\
\hline HCNG & Hydrogen-natural gas blend \\
\hline imep & Indicated mean effective pressure [Pa] \\
\hline LHV & Lower heating value $\left[\mathrm{MJ} / \mathrm{kg}\right.$ or $\left.\mathrm{MJ} / \mathrm{Nm}^{3}\right]$ \\
\hline MAP & Manifold absolute pressure \\
\hline MBT & Maximum brake torque \\
\hline NG & Natural gas \\
\hline NEDC & New European driving cycle \\
\hline NOx & Nitrogen oxides \\
\hline $\mathrm{PAH}$ & Polycyclic aromatic hydrocarbons \\
\hline $\mathrm{R}$ & Flame front position [m] \\
\hline rpm & Revolutions per minute \\
\hline S & Flame speed $[\mathrm{m} / \mathrm{s}]$ \\
\hline $\mathrm{t}$ & Time $[\mathrm{s}]$ \\
\hline $\mathrm{T}$ & Torque $[\mathrm{N} \mathrm{m}]$ \\
\hline THC & Total unburned hydrocarbon \\
\hline $\mathrm{u}_{l}$ & Unstretched laminar burning velocity [m/s] \\
\hline $\mathrm{V}$ & Volume $\left[\mathrm{m}^{3}\right]$ \\
\hline WOT & Wide open throttle \\
\hline \multicolumn{2}{|c|}{ Greek symbols } \\
\hline$\alpha$ & Mole number of NG [mol] \\
\hline$\beta$ & Mole number of hydrogen [mol] \\
\hline$\Delta \mathrm{h}_{r}$ & Enthalpy of reaction $[\mathrm{kJ} / \mathrm{mol}]$ \\
\hline$\kappa$ & Stretch rate $[1 / \mathrm{s}]$ \\
\hline$\lambda$ & Relative air-fuel ratio [-] \\
\hline$\phi$ & Equivalence ratio [-] \\
\hline $\bar{\sigma}$ & Standard deviation \\
\hline \multicolumn{2}{|c|}{ Subscripts } \\
\hline $\mathrm{a}$ & Air \\
\hline $\mathrm{b}$ & Burned \\
\hline $\mathrm{d}$ & Displacement \\
\hline $\mathrm{f}$ & Fuel \\
\hline 1 & Laminar \\
\hline $\operatorname{mix}$ & Mixture \\
\hline $\mathrm{n}$ & Stretched \\
\hline $\mathrm{S}$ & Unstretched \\
\hline stoich & Stoichiometric \\
\hline $\operatorname{tr}$ & Turbolent \\
\hline $\mathrm{u}$ & Unburned \\
\hline vol & Volumetric \\
\hline
\end{tabular}




\section{References}

Bakker, S. (2010). Hydrogen patent portfolios in the automotive industry - the search for promising storage methods, Int. J. of Hydrogen Energy 35: 6784-6793.

Barbir, F. (2005). Pem electrolysis for production of hydrogen from renewable energy sources, Solar Energy 78: 661-669.

Barlow, T., Latham, S., McCrae, I. \& Boulter, P. (2009). A reference book of driving cycles for use in the measurement of road vehicle emissions.

URL: http://www.dft.gov.uk/pgr/roads/environment/emissions/ppr-354.pdf

Bartels, J. R., Pate, M. B. \& Olson, N. K. (2010). An economic survey of hydrogen production from conventional and alternative energy sources, Int. J. of Hydrogen Energy 35: 8371-8384.

Chen, Z. (2009). Effects of hydrogen addition on the propagation of spherical methane/air fames: A computational study, Int. Journal Hydrogen Energy 34: 6558-6567.

Francfort, J. \& Karner, D. (2006). Hydrogen ice vehicle testing activities, SAE paper (2006-01-0433).

Genovese, A., Contrisciani, N., Ortenzi, F. \& Cazzola, V. (2011). On road experimental tests of hydrogen/natural gas blends on transit buses, Int. J. of Hydrogen Energy 36: 1775-1783.

Glassman, I. \& Yetter, R. A. (2008). Combustion, fourth edn, Academic press, San Diego.

Hoekstra, R., Collier, K., Mulligan, N. \& Chew, L. (1995). Experimental study of a clean burning vehicle fuel, Int. J. Hydrogen Energy 20: 737-745.

Hu, E., Huang, Z., Liu, B., Zheng, J. \& Gu, X. (2009). Experimental study on combustion characteristics of a spark-ignition engine fueled with natural gas hydrogen blends combining with egr, Int. J. Hydrogen Energy 34: 1035-1044.

Huang, B., Hu, E., Huang, Z., Zheng, J., Liu, B. \& Jiang, D. (2009). Cycle-by-cycle variations in a spark ignition engine fuelled with natural gas-hydrogen blends combined with egr, Int. J. Hydrogen Energy 34: 8405-8414.

IANGV (2011). Natural gas vehicle statistics.

URL: www.iangv.org

Ilbas, M., Crayford, A., Yilmaz, I., Bowen, P. \& Syred, N. (2006). Laminar-burning velocities of hydrogen-air and hydrogen-methane-air mixtures: An experimental study, Int. J. Hydrogen Energy 31: 1768-1779.

Karim, G. A., Wierzba, I. \& Al-Alousi, Y. (1996). Methane-hydrogen mixtures as fuels, Int. J. Hydrogen Energy 21: 625-631.

Ma, F., Wang, M., Jiang, L., Chen, R., Deng, J., Naeve, N. \& Zhao, S. (2010). Performance and emission characteristics of a turbo charged cng engine fueled by hydrogen-enriched compressed natural gas with high hydrogen ratio, Int. J. Hydrogen Energy 35: 6438-6447.

Ma, F., Wang, Y., Liu, H., Li, Y., Wang, J. \& Ding, S. (2008). Effects of hydrogen addition on cycle-by-cycle variations in a lean burn natural gas spark-ignition engine, Int. J. Hydrogen Energy 33: 823-831.

Mandilas, C., Ormsby, M., Sheppard, C. \& Woolley, R. (2007). Effects of hydrogen addition on laminar and turbulent premixed methane and iso-octane air flames, Proceedings of the Combustion Institute 31: 1443-1450. 
Mariani, A., Morrone, B. \& Unich, A. (2011). Numerical evaluation of internal combustion spark ignition engines performance fuelled with hydrogen - natural gas blends, Int. J. Hydrogen Energy p. doi:10.1016/j.ijhydene.2011.10.082.

Markstein, G. (1964). Nonsteady Flame Propagation, Pergamon Press.

Miao, H., Jiao, Q., Huang, Z. \& Jiang, D. (2009). Measurement of laminar burning velocities and markstein lengths of diluted hydrogen-enriched natural gas, Int. J. Hydrogen Energy 34: 507-518.

Nagalingam, B., Duebel, F. \& Schmillen, K. (1983). Performance study using natural gas, hydrogen-supplemented natural gas and hydrogen in avl research engine, Int. J. Hydrogen Energy 8: 715-720.

Prati, M. V., Costagliola, M. A., Torbati, R., Unich, A., Mariani, A., Morrone, B. \& Gerini, A. (2011). Combustion analysis of a sparl ignition engine fuelled with natural gas-hydrogen blends, WHTC.

Prati, M. V., Mariani, A., Torbati, R., Unich, A., Costagliola, M. A. \& Morrone, B. (2011). Emissions and combustion behavior of a bi-fuel gasoline and natural gas spark ignition engine, SAE Int. Journal of Fuels and Lubricants 4: 328-338.

Ridell, B. (2006). Malmö hydrogen and cng/hydrogen filling station and hythane bus project, WHEC.

Ristovski, Z., Morawska, L., Ayoko, G., Johnson, G., Gilbert, D. \& Greenaway, C. (2004). Emissions from a vehicle fitted to operate on either petrol or compressed natural gas, Science of the Total Environment 323: 179-194.

Sierens, R. \& Rosseel, E. (2000). Variable composition hydrogen/natural gas mixtures for increased engine efficiency and decreased emissions, Journal of Engineering for Gas Turbines and Power 122: 135-140.

Sørensen, B. (2005). Hydrogen and Fuel Cells.

Ulleberg (2003). Modeling of advanced alkaline electrolyzers: a system simulation approach, Int. J. of Hydrogen Energy 28: 21-33.

Wang, J., Chen, H., Liu, B. \& Huang, Z. (2008). Study of cycle-by-cycle variations of a spark ignition engine fuelled with natural gas-hydrogen blends, Int. J. Hydrogen Energy 33: $4876-4883$. 


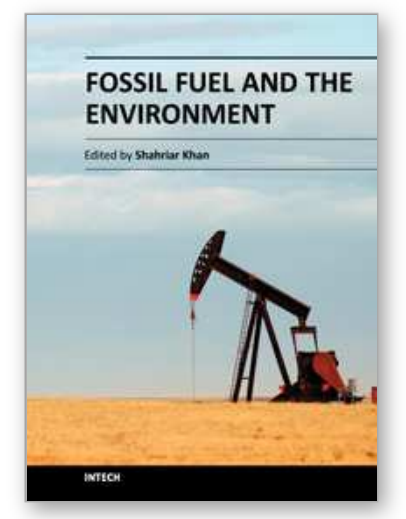

\author{
Fossil Fuel and the Environment \\ Edited by Dr. Shahriar Khan
}

ISBN 978-953-51-0277-9

Hard cover, 304 pages

Publisher InTech

Published online 14, March, 2012

Published in print edition March, 2012

The world today is at crossroads in terms of energy, as fossil fuel continues to shape global geopolitics. Alternative energy has become rapidly feasible, with thousands of wind-turbines emerging in the landscapes of the US and Europe. Solar energy and bio-fuels have found similarly wide applications. This book is a compilation of 13 chapters. The topics move mostly seamlessly from fuel combustion and coexistencewith renewable energy, to the environment, and finally to the economics of energy, and food security. The research and vision defines much of the range of our scientific knowledge on the subject and is a driving force for the future. Whether feasible or futuristic, this book is a great read for researchers, practitioners, or just about anyone with an enquiring mind on this subject.

\title{
How to reference
}

In order to correctly reference this scholarly work, feel free to copy and paste the following:

Antonio Mariani, Biagio Morrone and Andrea Unich (2012). A Review of Hydrogen-Natural Gas Blend Fuels in Internal Combustion Engines, Fossil Fuel and the Environment, Dr. Shahriar Khan (Ed.), ISBN: 978-953-510277-9, InTech, Available from: http://www.intechopen.com/books/fossil-fuel-and-the-environment/a-review-ofuse-of-hcng-fuels-in-internal-combustion-engines

\section{INTECH}

open science | open minds

\section{InTech Europe}

University Campus STeP Ri Slavka Krautzeka 83/A 51000 Rijeka, Croatia Phone: +385 (51) 770447 Fax: +385 (51) 686166 www.intechopen.com

\section{InTech China}

Unit 405, Office Block, Hotel Equatorial Shanghai No.65, Yan An Road (West), Shanghai, 200040, China 中国上海市延安西路65号上海国际贵都大饭店办公楼 405 单元 Phone: +86-21-62489820

Fax: +86-21-62489821 
(C) 2012 The Author(s). Licensee IntechOpen. This is an open access article distributed under the terms of the Creative Commons Attribution 3.0 License, which permits unrestricted use, distribution, and reproduction in any medium, provided the original work is properly cited. 